\title{
Metal Ion Selectivity of Kojate Complexes: A Theoretical Study
}

\author{
Sarita Singh, Jyoti Singh, Sunita Gulia, and Rita Kakkar \\ Department of Chemistry, University of Delhi, Delhi 110 007, India \\ Correspondence should be addressed to Rita Kakkar; rkakkar@chemistry.du.ac.in
}

Received 23 March 2013; Accepted 9 June 2013

Academic Editors: A. Kokalj, G. Pacchioni, and J. R. Sabin

Copyright (C) 2013 Sarita Singh et al. This is an open access article distributed under the Creative Commons Attribution License, which permits unrestricted use, distribution, and reproduction in any medium, provided the original work is properly cited.

\begin{abstract}
Density functional calculations have been performed on four-coordinate kojate complexes of selected divalent metal ions in order to determine the affinity of the metal ions for the kojate ion. The complexation reactions are characterized by high energies, showing that they are highly exothermic. It is found that $\mathrm{Ni}$ (II) exhibits the highest affinity for the kojate ion, and this is attributed to the largest amount of charge transfer from the ligand to the metal ion. The $\mathrm{Ni}$ (II) complex has distorted square planar structure. The HOMOs and LUMOs of the complexes are also discussed. All complexes display a strong band at $\sim 1500 \mathrm{~cm}^{-1}$ corresponding to the stretching frequency of the weakened carbonyl bond. Comparison of the complexation energies for the two steps shows that most of the complexation energy is realized in the first step. The energy released in the second step is about one-third that of the first step.
\end{abstract}

\section{Introduction}

Kojic acid, a $\gamma$-pyrone derivative $\left(\mathrm{C}_{6} \mathrm{H}_{6} \mathrm{O}_{4}\right.$; 5-hydroxy-2(hydroxymethyl)-4-pyrone), is a natural heterocyclic chelating agent found in fermented food. It forms stable, waterinsoluble chelates with metal cations such as $\mathrm{Fe}(\mathrm{II})$ and $\mathrm{Cu}(\mathrm{II})[1-3]$. The chelates have reasonable hydrolytic stability, neutral charge, and significant lipophilicity [4]. Anions of kojic acid and its derivatives behave as bidentate ligands and coordinate to iron(III) via the carbonyl and phenolic hydroxyl oxygens [5]. Kojic acid is identified and quantitatively determined gravimetrically by the formation of characteristic light-green copper kojate crystals.

Besides its use for analytical purposes, the chelating ability of kojic acid plays a significant role in its antimicrobial, antifungal, and antineoplastic activities [6-8]. The in vivo studies of $\mathrm{Mn}$ (II) and $\mathrm{Zn}$ (II) kojic complexes proved them to be potential radioprotective agents against lethal doses of $\gamma$-irradiation in mice [9]. The polarographic, potentiometric, and zone electrophoresis investigations of chelates of $\mathrm{Cd}(\mathrm{II})$ with kojic acid have been reported [10]. Wiley et al. [3] synthesized and determined the magnetic susceptibilities of $\mathrm{Cu}(\mathrm{II}), \mathrm{Ni}(\mathrm{II}), \mathrm{Co}(\mathrm{II}), \mathrm{Fe}(\mathrm{II})$, and $\mathrm{Mn}(\mathrm{II})$ kojate complexes. The complexing behavior of kojic acid with $\mathrm{Cu}(\mathrm{II}), \mathrm{Zn}(\mathrm{II})$, $\mathrm{Ni}(\mathrm{II})$, and $\mathrm{Co}(\mathrm{II})$ has also been reported in dioxane-water media $[11,12]$.
Due to their strong chelating ability, kojic acid and its derivatives play a strong role in $\mathrm{Fe}(\mathrm{III})$ and $\mathrm{Al}(\mathrm{III})$ overload pathologies. They also behave as tyrosinase inhibitors. Several experimental and density functional theory (DFT) studies on kojic acid complexes have been reported in the recent literature [13-19]. These include studies on complexes with several metal ions, including $\mathrm{Be}(\mathrm{II}), \mathrm{Cu}(\mathrm{II}), \mathrm{Fe}(\mathrm{III}), \mathrm{Al}(\mathrm{III})$, and $\mathrm{Ru}(\mathrm{III})$. The transport of the antidiabetic $\mathrm{VO}^{2+}$ complex of kojic acid derivatives in the blood serum has also been investigated $[20,21]$.

In view of the various applications of kojate acid complexes, we have investigated the metal ion selectivity of the kojate ion toward selected divalent transition metal ions. These metal ions are of importance in bioinorganic chemistry because of the abundance of their metalloprotein complexes. The selected seven metals (Scheme 1) are also the major pollutants of the environment. It is hoped that the understanding of the selective binding of these metals may ultimately lead to the development of methods for their successful removal from the environment.

Density functional methods comprise some of the reliable and precise theoretical methods suitable for studying transitional metal complexes. A practical approach is the use of the generalized gradient approximation (GGA), which gives good results at relatively low computational cost [22]. 


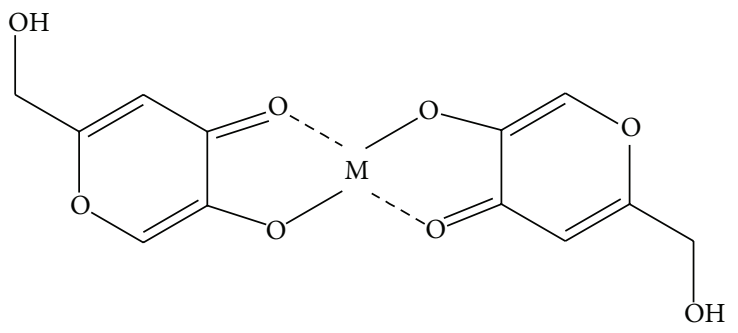

$\mathrm{M}=\mathrm{Mn}, \mathrm{Co}, \mathrm{Ni}, \mathrm{Cu}, \mathrm{Zn}, \mathrm{Cd}$, and $\mathrm{Hg}$

SCHEME 1

\section{Computational Details}

The DFT approach, using the GGA-PBE functional [23] in the $\mathrm{DMol}^{3}$ code [24-27] available from Accelrys Inc., was used for the calculations reported in this paper. A few of the metal ions ( $\mathrm{Mn}(\mathrm{II}), \mathrm{Co}(\mathrm{II})$, and $\mathrm{Cu}(\mathrm{II})$ ) represent open shell systems. Therefore, we performed unrestricted calculations on all complexes using numerical basis sets of double- $\zeta$ quality plus polarization functions (DNP) to describe the valence orbitals. This basis set is the numerical equivalent of the Gaussian basis $6-31 G^{* *}$, but is far more complete, leading to the reduction of the basis set superposition error (BSSE) [28]. The BSSE for the DNP basis set was found to be comparable with that for the much larger 6-311+G-(3df,2pd) Gaussian basis set, and the upper limit of the mean error for the DNP basis set in conjunction with the PBE functional due to neglect of BSSE is less than $1 \mathrm{kcal} \mathrm{mol}^{-1}[29,30]$. This is much smaller than the energy quantities involved in the various processes studied here and may therefore be neglected.

The cores of the transition metal ions were modeled with DFT semicore potentials DSSP [31], which are specifically designed for DFT functions rather than HartreeFock calculations. Charge densities were calculated using the electrostatic-potential (ESP) fitting method [32]. Bond orders were calculated using Mayer's procedure [33], since the Mulliken method has well-known shortcomings because of the uncertainty in uniquely defining a charge-partitioning scheme [34] and the basis-size dependence of the calculated charge densities [35]. In a comparison of various LDA and GGA functionals for studying the bonding characteristics of the three isomeric copper(II) aminophenylhydroxamic acids, the GGA-PBE functional was found to perform best [35].

\section{Results and Discussion}

3.1. Structures of the Complexes. We have previously studied kojic acid and its anions [36]. Here, we have investigated the four-coordinate kojate complexes of the seven transition metal ions, $\mathrm{Mn}^{2+}, \mathrm{Co}^{2+}, \mathrm{Ni}^{2+}, \mathrm{Cu}^{2+}, \mathrm{Zn}^{2+}, \mathrm{Cd}^{2+}$, and $\mathrm{Hg}^{2+}$ (Scheme 1). Out of these, $\mathrm{Zn}^{2+}, \mathrm{Cd}^{2+}$, and $\mathrm{Hg}^{2+}$ are $d^{10}$ ions $\left({ }^{1} S\right)$, and hence there is no ambiguity in the spin state of their complexes, which are closed shell systems with singlet ground states. Copper is a $d^{9}$ ion $\left({ }^{2} D\right)$ and its complexes have doublet ground states. The situation becomes more complicated for $\mathrm{Mn}^{2+}, \mathrm{Co}^{2+}$, and $\mathrm{Ni}^{2+}$ ions, which may exist in their complexes both in high spin and low spin states [22].
Four coordinate complexes may have either square planar (cis or trans) or tetrahedral coordination geometries. Mn(II) can exist in low, intermediate, and high spin states, that is, doublet, quartet, and sextet. For Mn(II) complexes in the doublet state, all the geometries are distorted from their initial geometries, as shown in Table Ala (see Supporting Information available online at http://dx.doi.org/10.1155/ 2013/342783). The tetrahedral geometry is slightly preferred (by $0.7 \mathrm{kcal} \mathrm{mol}^{-1}$ ). In the quartet state, cis square planar is the preferred structure. For the sextet Mn(II) complexes, all geometries converged to distorted tetrahedral geometry. On the basis of the total energy for the $\mathrm{Mn}$ (II) kojate complexes of various multiplicities, the high spin sextet state is found to be the ground state.

For the doublet Co(II) complex, all initial geometries distorted to square planar, the trans isomer being more stable by $5.8 \mathrm{kcal} \mathrm{mol}^{-1}$, but the quartet state prefers the tetrahedral geometry. The low spin doublet state is found to be the ground state. For the singlet Ni(II) kojate complex, the cis and trans square planar complexes maintain their geometry after optimization, whereas the tetrahedral geometry optimizes to cis square planar. Thus, the cis square planar geometry is the most stable structure for $\mathrm{Ni}$ (II) in the singlet state. For the triplet state, the initial cis square planar geometry changes to distorted tetrahedral, whereas the trans structure maintains its geometry, making tetrahedral the most stable structure for $\mathrm{Ni}$ (II) in the triplet state. This is less stable than the ground state singlet by $10.7 \mathrm{kcal} \mathrm{mol}^{-1}$. The doublet $\mathrm{Cu}$ (II) kojate complexes prefer the square planar geometry, as evident from the optimization of the initial tetrahedral structure to trans square planar. Here, too, the cis isomer is slightly preferred.

In case of singlet $\mathrm{Zn}(\mathrm{II}), \mathrm{Cd}(\mathrm{II})$, and $\mathrm{Hg}(\mathrm{II})$ kojate complexes, the preferred geometries are distorted tetrahedral. In case of $\mathrm{Hg}(\mathrm{II})$, the coordination number of the metal also changes from 4 to 2 . In these bicoordinated complexes, $\mathrm{Hg}$ (II) acts as a bridge between the two kojate ions. Hence, we infer that $\mathrm{Zn}$ (II) clearly prefers the tetrahedral geometry, but the larger Cd(II) does not show such strong preference, since the trans square planar structure is less stable by only $2.3 \mathrm{kcal} \mathrm{mol}^{-1}$. In contrast to $\mathrm{Cd}(\mathrm{II})$ which is four coordinated, $\mathrm{Hg}$ (II) prefers to be bicoordinated. It is found to form mostly linear complexes owing to relativistic effects, which result in a large $6 s-6 p$ energy gap, limiting effective hybrid orbital formation to linear $s p$ [37].

The preferred multiplicities and geometries of the various complexes are summarized in Table 1 . We observe that, except 


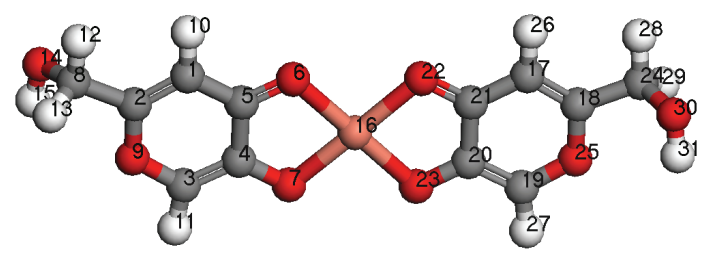

FIgURE 1: Numbering scheme for the complexes.

TABLE 1: Calculated spin multiplicities, preferred geometries, and complexation energies $\left(\mathrm{kcal} \mathrm{mol}^{-1}\right)$ for the kojate complexes.

\begin{tabular}{lccc}
\hline Metal ion & $\begin{array}{c}\text { Spin } \\
\text { multiplicity }\end{array}$ & Geometry & $\begin{array}{c}\text { Complexation } \\
\text { energy }\end{array}$ \\
\hline $\mathrm{Mn}(\mathrm{II})$ & Sextet & Tetrahedral & -597.9 \\
$\mathrm{Co}(\mathrm{II})$ & Doublet & trans square planar & -686.4 \\
$\mathrm{Ni}(\mathrm{II})$ & Singlet & cis square planar & -698.1 \\
$\mathrm{Cu}(\mathrm{II})$ & Doublet & cis square planar & -677.7 \\
$\mathrm{Zn}(\mathrm{II})$ & Singlet & Tetrahedral & -638.9 \\
$\mathrm{Cd}(\mathrm{II})$ & Singlet & Tetrahedral & -580.1 \\
$\mathrm{Hg}(\mathrm{II})$ & Singlet & Tetrahedral & -609.8 \\
\hline
\end{tabular}

for the metal ions having completely filled or half-filled $d$ orbitals, the preferred geometry is square planar $\left(D_{4 h}\right)$. In a square planar field, the $3 d$ orbitals of the metal are split into four levels, which are, in order of increasing energy, $\left\{d_{x z}, d_{y z}\right\}\left(e_{g}\right)<d_{z^{2}}\left(a_{1 g}\right)<d_{x y}\left(b_{2 g}\right)<d_{x^{2}-y^{2}}\left(b_{1 g}\right)$. The important feature of the splitting is that the $d_{x^{2}-y^{2}}$ orbital goes to very high energy, as it is in the crowded molecular $(x y)$ plane, resulting in strong electronic repulsion of the electrons of the metal and the ligands. Therefore, the most favorable configuration for forming square planar complexes is low spin $d^{8}\left(\mathrm{Ni}^{2+}\right)$, as there is further stabilization of a closed shell singlet over an open shell triplet state. The $d^{9}\left(\mathrm{Cu}^{2+}\right)$ and $d^{7}$ $\left(\mathrm{Co}^{2+}\right)$ cases are not so favorable. According to the valence bond theory, the vacant $d_{x^{2}-y^{2}}$ orbital can form hybrid orbitals with $4 s\left(a_{1 g}\right)$ and two $4 p$ orbitals $\left\{p_{x}, p_{y}\right\}\left(e_{u}\right)$, giving $d s p^{2}$ hybrid orbitals. These vacant orbitals can accommodate electrons from the ligand.

For the majority of systems, that is, the completely filled $d^{10}$ and half-filled $d^{5}$ ones, the bonding is tetrahedral $\left(T_{d}\right)$. The electron configuration of $\mathrm{Zn}(\mathrm{II})$ is $3 d^{10}$, and hence the ground state is singlet. It coordinates with ligands using the $4 s$ and $4 p$ orbitals in $s p^{3}$ hybrid orbitals. According to the valence shell electron pair repulsion (VSEPR) theory, tetrahedral configurations are favored for the $\mathrm{Zn}$ (II) four-coordinate complexes, as in $\left[\mathrm{ZnCl}_{4}\right]^{2-}$. In this hybridization scheme, the relatively low energy $3 d_{x^{2}-y^{2}}$ orbital is replaced by a higher energy $4 p_{z}$ orbital, and hence charge transfer from the lowlying ligand orbitals is not so facile. For the other $d^{10}$ systems (Cd(II) and $\mathrm{Hg}(\mathrm{II})$ ), the situation is similar, except that $\mathrm{Hg}(\mathrm{II})$
TABLE 2: Calculated Mayer's bond orders of the metal oxygen bonds in the complexes.

\begin{tabular}{lccccccc}
\hline Bond & $\mathrm{Mn}(\mathrm{II})$ & $\mathrm{Co}(\mathrm{II})$ & $\mathrm{Ni}(\mathrm{II})$ & $\mathrm{Cu}(\mathrm{II})$ & $\mathrm{Zn}(\mathrm{II})$ & $\mathrm{Cd}(\mathrm{II})$ & $\mathrm{Hg}(\mathrm{II})$ \\
\hline $\mathrm{O}_{6}-\mathrm{M}_{16}$ & 0.421 & 0.625 & 0.597 & 0.562 & 0.463 & 0.366 & 0.314 \\
$\mathrm{O}_{7}-\mathrm{M}_{16}$ & 0.555 & 0.687 & 0.653 & 0.647 & 0.573 & 0.479 & 0.564 \\
$\mathrm{O}_{22}-\mathrm{M}_{16}$ & 0.419 & 0.625 & 0.607 & 0.563 & 0.463 & 0.367 & 0.317 \\
$\mathrm{O}_{23}-\mathrm{M}_{16}$ & 0.557 & 0.687 & 0.647 & 0.645 & 0.573 & 0.478 & 0.561 \\
\hline
\end{tabular}

prefers linear coordination. The preference for the high spin state for $\mathrm{Mn}(\mathrm{II})$ is easily understood on the basis of the higher stability associated with half-filled configurations.

Hence, for the zinc triad and $\mathrm{Mn}(\mathrm{II})$, we infer that the preferred geometries are tetrahedral, but the rest of the metal ions form square planar complexes with the kojate ion.

3.2. Complexation Energies. Due to the preference for low spin multiplicities for all the metal complexes, except Mn(II), we confine further discussion to the low spin complexes of all the metal ions, except $\mathrm{Mn}(\mathrm{II})$, for which the high spin sextet is considered.

Table 1 gives the complexation energies (see Appendix Table A1 for complete data) of the kojate complexes of the metal ions, calculated from the expression

$$
\Delta E=E_{\text {complex }}-E_{\mathrm{M}^{2+}}-2 E_{\text {kojate }},
$$

where $E_{\text {complex }}$ is the computed energy of the complex, $E_{\mathrm{M}^{2+}}$ is the energy of the metal ion, and $E_{\text {kojate }}$ is the energy of the kojate ligand $\left(-333863.8 \mathrm{kcal} \mathrm{mol}^{-1}\right)$. The metal ion energies were computed for the ground state consistent with the observed multiplicities in the complexes. The computed metal ion energies are $-120.921277,-165.812843$, $-192.450044,-221.438031,-253.424219,-88.898031$, and $-227.558679 \mathrm{Ha}$, respectively, for $\mathrm{Mn}(\mathrm{II}), \mathrm{Co}(\mathrm{II}), \mathrm{Ni}(\mathrm{II})$, $\mathrm{Cu}(\mathrm{II}), \mathrm{Zn}(\mathrm{II}), \mathrm{Cd}(\mathrm{II})$, and $\mathrm{Hg}(\mathrm{II}) . E_{\text {complex }}$ is the energy of the most stable complex of the concerned metal.

A large variation in the complexation energies is clear from Table 1. The complexation energies are negative in all the cases implying that the reactions are highly exothermic.

$\mathrm{Ni}$ (II) appears to have the largest affinity for the kojate ion, followed by $\mathrm{Co}(\mathrm{II})$ and $\mathrm{Cu}(\mathrm{II})$. Amongst the zinc triad, the order of stabilities is $\mathrm{Zn}(\mathrm{II})>\mathrm{Hg}(\mathrm{II})>\mathrm{Cd}(\mathrm{II})$. The sequence of stability constants for complexes of various metal ions is expected to depend on the ionic radii and electronegativities 
TABLE 3: HOMO and LUMO plots, along with their energies (eV), for the $1: 2$ complexes.

\begin{tabular}{|c|c|c|}
\hline & HOMO & LUMO \\
\hline \multirow[t]{2}{*}{$\mathrm{Mn}(\mathrm{II})$} & & \\
\hline & -4.079 & -2.428 \\
\hline \multirow[t]{2}{*}{$\mathrm{Co}(\mathrm{II})$} & & \\
\hline & -3.983 & -2.591 \\
\hline \multirow[t]{2}{*}{$\mathrm{Ni}(\mathrm{II})$} & & \\
\hline & -4.118 & -2.308 \\
\hline \multirow[t]{2}{*}{$\mathrm{Cu}(\mathrm{II})$} & & \\
\hline & -4.628 & -3.352 \\
\hline \multirow[t]{2}{*}{$\mathrm{Zn}(\mathrm{II})$} & & \\
\hline & -4.993 & -2.257 \\
\hline \multirow[t]{2}{*}{$\mathrm{Cd}(\mathrm{II})$} & & \\
\hline & -4.936 & -2.182 \\
\hline \multirow[t]{2}{*}{$\mathrm{Hg}(\mathrm{II})$} & & \\
\hline & -4.986 & -2.256 \\
\hline
\end{tabular}

of the respective metal ions. The explanations of factors determining the specificity of metal ion uptake are also often based on quantitative or semiquantitative principles, such as the HSAB (hard and soft acids and bases) principle of Parr and Pearson [38, 39], the Irving-Williams series of stability constants $[40,41]$, and the abundance of transition metals coordination geometries in the experimentally determined molecular structures $[42,43]$. The Irving-Williams order of stability constants for the divalent metal ions of the first transition series is

$$
\mathrm{Mn}(\mathrm{II})<\mathrm{Co}(\mathrm{II})<\mathrm{Ni}(\mathrm{II})<\mathrm{Cu}(\mathrm{II})<\mathrm{Zn}(\mathrm{II}) .
$$


TABLE 4: Calculated metal-oxygen bond lengths in the complexes.

\begin{tabular}{lccccccc}
\hline & $\mathrm{Mn}(\mathrm{II})$ & $\mathrm{Co}(\mathrm{II})$ & $\mathrm{Ni}(\mathrm{II})$ & $\mathrm{Cu}(\mathrm{II})$ & $\mathrm{Zn}(\mathrm{II})$ & $\mathrm{Cd}(\mathrm{II})$ & $\mathrm{Hg}(\mathrm{II})$ \\
\hline $\mathrm{M}_{16}-\mathrm{O}_{6}$ & 2.124 & 1.914 & 1.884 & 1.987 & 2.053 & 2.285 & 2.445 \\
$\mathrm{M}_{16}-\mathrm{O}_{7}$ & 2.028 & 1.900 & 1.866 & 1.946 & 1.979 & 2.190 & 2.201 \\
$\mathrm{M}_{16}-\mathrm{O}_{22}$ & 2.125 & 1.914 & 1.873 & 1.987 & 2.053 & 2.286 & 2.437 \\
$\mathrm{M}_{16}-\mathrm{O}_{23}$ & 2.027 & 1.900 & 1.874 & 1.946 & 1.979 & 2.191 & 2.205 \\
\hline
\end{tabular}

The complexation energies of the metal ion complexes, calculated in this work, follow the order:

$$
\begin{aligned}
\mathrm{Cd}(\mathrm{II}) & <\mathrm{Mn}(\mathrm{II})<\mathrm{Hg}(\mathrm{II})<\mathrm{Zn}(\mathrm{II})<\mathrm{Cu}(\mathrm{II}) \\
& <\mathrm{Co}(\mathrm{II})<\mathrm{Ni}(\mathrm{II}) .
\end{aligned}
$$

This order can be explained on the basis of the HSAB principle. The ligand in question, kojate, contains negatively charged carboxylate oxygens, and is hence hard (according to the HSAB classification), and should not prefer the soft metal ions, $\mathrm{Cd}(\mathrm{II})$ and $\mathrm{Hg}(\mathrm{II})$. The binding affinity has been found to be largest for $\mathrm{Ni}$ (II) (violating the Irving-Williams order). The unusual stability of $\mathrm{Ni}(\mathrm{II})$-kojate complexes is also apparent from the following arguments. Taking the $d^{10}$ systems as a baseline (no crystal field stabilization), it is seen from the calculated stability order that there is extra stability for $\mathrm{Cu}(\mathrm{II}), \mathrm{Co}(\mathrm{II})$, and $\mathrm{Ni}(\mathrm{II})$. The crystal field correction increases to a maximum at $\mathrm{Cu}(\mathrm{II})$, before falling abruptly to zero at $\mathrm{Zn}$ (II) $[44,45]$. $\mathrm{Co}$ (II), with a smaller crystal field correction than $\mathrm{Ni}(\mathrm{II})$, is expected to form stronger complexes than $\mathrm{Ni}(\mathrm{II})$, but the order found for kojate complexes is the opposite. Thus, there is a special affinity of the kojate ion for $\mathrm{Ni}(\mathrm{II})$.

3.3. Charge Population Analysis. The ESP-fitted charges on the metal ion present in the respective kojate complexes are $0.950,0.609,0.265,0.592,0.889,1.099$, and 0.759 , respectively, for $\mathrm{Mn}, \mathrm{Co}, \mathrm{Ni}, \mathrm{Cu}, \mathrm{Zn}, \mathrm{Cd}$, and $\mathrm{Hg}$. It can be observed that the positive charge on the metal ion decreases from its value of +2 in the free state on coordination with the kojate ion. This indicates that electron transfer from the ligands to the metal ion occurs during the formation of the coordination bond. The charge transfer is largest for the Ni(II) complex and is least for $\mathrm{Cd}(\mathrm{II})$. This is consistent with $\mathrm{Ni}$ (II) forming the strongest complex and $\mathrm{Cd}(\mathrm{II})$ forming the weakest complex according to the complexation energies (Table 1). In fact, the complexation energies follow almost the same order as the charge transfer. Thus, the coordinate bonding is responsible for complex formation, where the mechanism is charge transfer from the ligand to the metal ion.

The Mayer bond orders for the metal-chelate bonds are given in Table 2, and Figure 1 gives the numbering scheme.

Considerable asymmetry in the bond orders can be seen, except in the trans square planar Co(II) complex, where the corresponding bond orders in the cis square planar structure are equivalent. The $\mathrm{Zn}(\mathrm{II})$ tetrahedral complex is also symmetrical.

Table 3 displays the HOMO and LUMO plots for the various complexes. It is generally expected that the HOMOs of the complexes comprise the ligand orbitals and the LUMOs those
TABLE 5: Calculated vibrational wave number $\left(\mathrm{cm}^{-1}\right)$ and intensities $\left(\mathrm{km} \mathrm{mol}^{-1}\right)$ for the most intense bands (carbonyl stretch) of the complexes.

\begin{tabular}{lcc}
\hline & $\bar{\nu}$ & $I$ \\
\hline $\mathrm{Mn}(\mathrm{II})$ & 1567 & 625 \\
$\mathrm{Co}(\mathrm{II})$ & 1551 & 368 \\
$\mathrm{Ni}(\mathrm{II})$ & 1481 & 480 \\
$\mathrm{Cu}(\mathrm{II})$ & 1558 & 887 \\
$\mathrm{Zn}(\mathrm{II})$ & 1577 & 640 \\
$\mathrm{Cd}(\mathrm{II})$ & 1541 & 600 \\
$\mathrm{Hg}(\mathrm{II})$ & 1552 & 472 \\
\hline
\end{tabular}

of the metal. However, for Mn(II) we find that, except for the coordinating oxygens, there is hardly any contribution from the ligand in the HOMO. The LUMO, however, has more contribution from the ligand. This is because of the donation of electron density from the ligand to the metal ion, making the latter electron rich and leaving the ligand electron deficient. The same trend is repeated for the Ni(II) complex. The $\mathrm{Co}$ (II) complex has both the HOMO and LUMO centered on the metal ion. In the $\mathrm{Zn}$ (II) and $\mathrm{Cd}$ (II) complexes, the metal ion is neither present in the HOMO nor the LUMO, but the LUMO of the $\mathrm{Hg}(\mathrm{II})$ complex is centered on the metal ion. Thus, the metal complexes show a large variation in their frontier orbitals.

3.4. Bond Lengths. Table 4 lists the metal-oxygen bond lengths in the various kojate complexes investigated in this work. The metal-ligand complexes show the same trends as before, that is, only the $\mathrm{Co}$ (II) and $\mathrm{Zn}$ (II) complexes are symmetrical; the others show considerable asymmetry.

3.5. Vibrational Analysis. The calculated vibrational frequencies and spectra for the complexes are given in the Supporting Information. All the spectra are characterized by a strong band at $\sim 1500 \mathrm{~cm}^{-1}$, which corresponds to the carbonyl stretching mode modified by complexation to the metal ion. Table 5 lists the vibrational wavenumber and intensity of this band for each of the complexes. The smallest vibrational wavenumber for the $\mathrm{Ni}$ (II) complex signifies the greatest weakening of the carbonyl bond in this case owing to the larger charge transfer to the metal ion.

3.6. Stepwise Complex Formation. To gain better insight into the relative affinities of the various metal ions, we considered the energetics of the various steps involved in the complexation process. The initial step is the deprotonation of kojic acid $(\mathrm{HL})$ to its anion (L). The energy difference $E_{\mathrm{L}}-E_{\mathrm{HL}}$ may be taken as the deprotonation energy for the gas phase reaction. The calculated value $\left(360.8 \mathrm{kcal} \mathrm{mol}^{-1}\right)$ is large.

We now focus on the relative energetics for the formation of $1: 1$ and $1: 2$ complexes. The complexation energies $\left(\Delta E=E_{\mathrm{ML}}-E_{\mathrm{M}^{2+}}-E_{\mathrm{kojate}}\right)$ for the formation of $1: 1 \mathrm{com}-$ plexes of $\mathrm{Mn}(\mathrm{II}), \mathrm{Co}(\mathrm{II}), \mathrm{Ni}(\mathrm{II}), \mathrm{Cu}(\mathrm{II}), \mathrm{Zn}(\mathrm{II}), \mathrm{Cd}(\mathrm{II})$, and $\mathrm{Hg}(\mathrm{II})$ are $-411.9,-472.6,-515.6,-488.7,-455.0,-410.4$, and $-455.0 \mathrm{kcal} \mathrm{mol}^{-1}$, respectively. The exothermicity of this step 
TABLE 6: Calculated metal oxygen bond lengths $(\AA)$ and bond orders in the complexes.

\begin{tabular}{|c|c|c|c|c|c|c|c|}
\hline Bond & $\mathrm{Mn}(\mathrm{II})$ & $\mathrm{Co}(\mathrm{II})$ & $\mathrm{Ni}(\mathrm{II})$ & $\mathrm{Cu}(\mathrm{II})$ & $\mathrm{Zn}(\mathrm{II})$ & $\mathrm{Cd}(\mathrm{II})$ & $\mathrm{Hg}(\mathrm{II})$ \\
\hline \multicolumn{8}{|l|}{$\mathrm{M}_{16}-\mathrm{O}_{8}$} \\
\hline Length & 1.972 & 1.855 & 1.915 & 1.955 & 1.979 & 2.269 & 2.532 \\
\hline Order & 0.727 & 0.792 & 0.541 & 0.581 & 0.630 & 0.428 & 0.252 \\
\hline \multicolumn{8}{|l|}{$\mathrm{M}_{16}-\mathrm{O}_{9}$} \\
\hline Length & 1.918 & 1.838 & 1.891 & 1.933 & 1.946 & 2.234 & 2.517 \\
\hline Order & 0.880 & 0.843 & 0.579 & 0.616 & 0.696 & 0.470 & 0.257 \\
\hline
\end{tabular}

is greater than the endothermicity of the deprotonation step, showing that $1: 1$ complex formation is thermodynamically feasible. The order of affinities for the kojate ion for the different metal ions is

$$
\begin{aligned}
\mathrm{Cd}(\mathrm{II})<\mathrm{Mn}(\mathrm{II})<\mathrm{Hg}(\mathrm{II}) & =\mathrm{Zn}(\mathrm{II})<\mathrm{Co}(\mathrm{II}) \\
& <\mathrm{Cu}(\mathrm{II})<\mathrm{Ni}(\mathrm{II})
\end{aligned}
$$

which is almost the same as that for the $1: 2$ complexes described in Section 3.2, with the exception that $\mathrm{Cu}$ (II) and $\mathrm{Co}$ (II) have exchanged their relative positions. The greatest affinity for $\mathrm{Ni}$ (II) is apparent from the first step itself. Interestingly, it may also be pointed out that, in general, about three-quarters of the overall exothermicity is produced with the entering of the first ligand molecule (e.g., for $\mathrm{Ni}(\mathrm{II})-515.6$ over $-698.1 \mathrm{kcal} \mathrm{mol}^{-1}$ ).

The formation of the $1: 2$ complex is not thermodynamically favored (for $\mathrm{Ni}(\mathrm{II})$, the overall complexation reaction is endothermic by $10.5 \mathrm{kcal} \mathrm{mol}^{-1}$ ), since this entails a second deprotonation. A reasonable explanation for the generally greater metal-ligand binding energy of the $1: 1$ adducts comes from the comparison of the optimized structures. As shown in Table 6 , the $1: 1$ complexes have significantly shorter M-O bonds than the bischelate analogues (Table 4), except for the case of the $\mathrm{Ni}$ (II) complex. Comparison with Table 2 for the bond orders confirms the same result; that is, the metal ligand bonding is stronger in the $1: 1$ complexes and weakens with the entry of the second ligand. The only exception is the $\mathrm{Ni}$ (II) complex, where the bond strengthens on addition of the second ligand, again confirming the strong affinity of this metal ion for the kojate ligand. For the other cases, the weakening of the metal oxygen bonds in the $1: 2$ complexes can be easily accounted for by the more effective positive charge of the $\mathrm{M}^{2+}$ ion in the first step, which is not yet quenched by the presence of a preexisting chelating anion. The ESP charge on the metal ion in the $1: 1$ complexes is $1.196,1.002,0.860$, $0.873,0.951,0.939$, and 0.555 , respectively, for $\mathrm{Mn}(\mathrm{II}), \mathrm{Co}(\mathrm{II})$, $\mathrm{Ni}(\mathrm{II}), \mathrm{Cu}(\mathrm{II}), \mathrm{Zn}(\mathrm{II}), \mathrm{Cd}(\mathrm{II})$, and $\mathrm{Hg}(\mathrm{II})$, showing that the positive charge on the metal ion is considerably reduced in the first step of the reaction itself, decreasing its affinity for the second ligand molecule. In this first step, the largest charge transfer is to $\mathrm{Mn}(\mathrm{II})$. However, for $\mathrm{Ni}(\mathrm{II})$, charge transfer from the ligand takes place in the second step also owing to its larger electrophilicity, whereas $\mathrm{Mn}$ (II) donates back some of its electron density to the ligand in the second step.

Finally, we also consider the HOMO-LUMO plots to see if they can give a clue to the greater stability of the $1: 1$ complexes. These are displayed in Table 7.
In general, the HOMOs of complexes consist of the ligand orbitals and the LUMOs comprise the vacant metal orbitals. In the present instance, the HOMO plots are similar for all cases (i.e., they are the $\pi$ orbitals of the ligand), the only exception being the $\mathrm{Ni}$ (II) complexes, in which they are similar to the LUMOs of the rest of the metal ion complexes and lie on the metal ion and the $p$-orbitals of the coordinating oxygens of the ligand.

We now explore the entry of the first ligand molecule in terms of the interacting orbitals for the two extreme casesthe metal ion forming the most stable complex, $\mathrm{Ni}$ (II) and the one forming the least stable one, that is, $\mathrm{Cd}$ (II). The final geometries of the two complexes are also different, square planar for the former and tetrahedral for the latter. $\mathrm{Ni}^{2+}$ has a triplet $\left({ }^{3} F_{4}\right)$ ground state, and the first empty orbital is the $4 s$ orbital. The HOMO of the kojate ion (Table 7) is a highenergy orbital consisting of the $\pi$ orbitals of the ring and the lone pairs of the two oxygens that coordinate with the metal ion. As the ligand orbitals approach the metal ion in the $x y$ plane, the energy of the $d_{x^{2}-y^{2}}$ orbital rises due to repulsion with the oxygen $p$ orbitals, leading to pairing of the electrons in the other $d$ orbitals. The ligand then donates electron density to the now empty $d_{x^{2}-y^{2}}$ orbital, as seen from the participation of the metal in the HOMO of the nickel complex (Table 7). The nickel ion is no longer electron deficient, as can be seen from its absence in the LUMO, which comprises the ligand $\pi^{*}$ orbitals. This agrees with the assumptions of the MO and VB theories, described in Section 3.1. We also note that the gap between the HOMO of the kojate ion $(1.030 \mathrm{eV})$ and the LUMO of the $\mathrm{Ni}(\mathrm{II})$ complex is the least, signifying that further electron transfer from the former can take place on entry of the second ligand molecule.

In contrast, for the $d^{10} \mathrm{Cd}(\mathrm{II})$ system, the $4 d$ orbitals are entirely occupied, and the vacant $5 s$ orbital is a higher energy. Hence, relatively less charge transfer from the ligand to the metal ion takes place, as seen from the negligible presence of the metal orbitals in the HOMO. The LUMO, thus, remains the $5 s$ orbital of the metal ion, along with the $p$ orbitals of the coordinating oxygen atoms, which remain intact. This again agrees with the discussion in Section 3.1.

\section{Conclusions}

Our study of metal ion complexes of selected metal ions with kojic acid has shown that $\mathrm{Ni}$ (II) has the greatest affinity for kojate ion and $\mathrm{Cd}$ (II) the least. Amongst the divalent metal ions of the zinc triad, no relationship between the atomic 
TABLE 7: HOMOs and LUMOs for the ligand and the $1: 1$ complexes, along with their energies (eV).

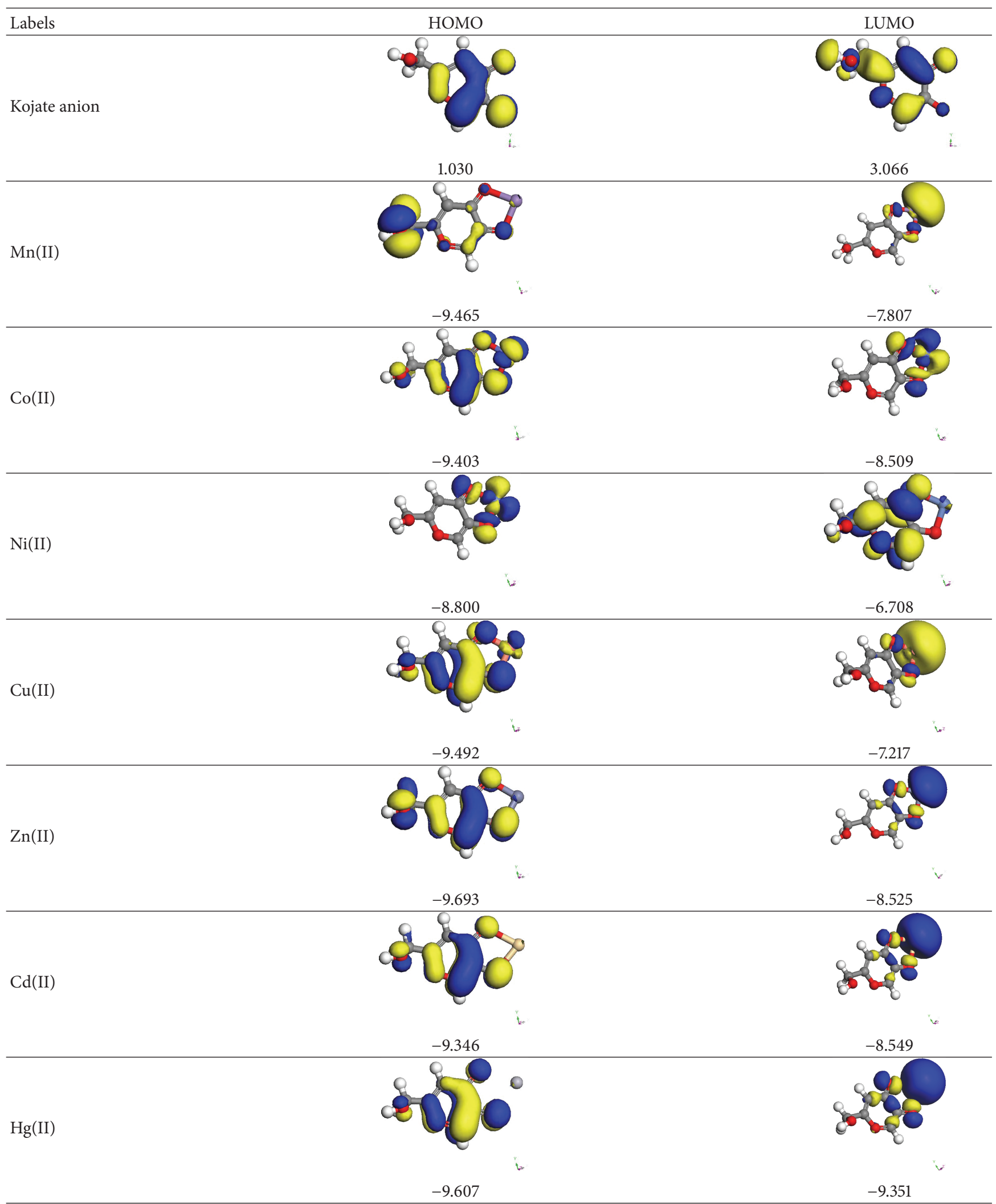


number and the complexation energy is found, $\mathrm{Zn}$ (II) forming the strongest complex and Cd(II) the weakest. For Ni(II), the complexation involves charge transfer from the ligand to the empty $d_{x^{2}-y^{2}}$ orbital, leading to strong bonding. Even after one ligand molecule coordinates with the metal ion, $\mathrm{Ni}$ (II) still has the capacity to coordinate with another kojate ion by accepting more electron density. The other metal ions do not show any such tendency.

\section{Conflict of Interests}

We certify that there is no conflict of interests with any financial organization regarding the material discussed in the paper.

\section{Acknowledgments}

The authors thank the University of Delhi's "Scheme to Strengthen R\&D Doctoral Research Program by Providing Funds to University Faculty."

\section{References}

[1] A. Beélik, "Kojic Acid," Advances in Carbohydrate Chemistry, vol. 48, pp. 145-183, 1956.

[2] S. A. Sallam, S. S. Haggag, and M. S. Masoud, "Thermodynamic parameters of ionization of kojic acid and its coordinating behaviour towards transition metals," Thermochimica Acta, vol. 168, pp. 1-7, 1990.

[3] J. W. Wiley, G. N. Tyson Jr., and J. S. Steller, “The configuration of complex kojates formed with some transition elements as determined by magnetic susceptibility measurements," Journal of the American Chemical Society, vol. 64, no. 4, pp. 963-964, 1942.

[4] P. Comba, "The relation between ligand structures, coordination stereochemistry, and electronic and thermodynamic properties," Coordination Chemistry Reviews, vol. 123, pp. 1-48, 1993.

[5] J. Šima, A. Bradiaková, and M. Antalík, "Photochemical properties of systems containing cytochrome $c$ and kojic acid," Journal of Photochemistry and Photobiology A, vol. 94, pp. 163-166, 1996.

[6] J. Brtko, L. Rondahl, M. Ficková, D. Hudecová, V. Eybl, and M. Uher, "Kojic acid and its derivatives: history and present state of art," Central European Journal of Public Health, vol. 12, supplement, pp. S16-S18, 2004.

[7] J. Bransová, J. Brtko, M. Uher, and L. Novotny, "Antileukemic activity of 4-pyranone derivatives," The International Journal of Biochemistry \& Cell Biology, vol. 27, pp. 701-706, 1995.

[8] L. Novotný, P. Rauko, M. Abdel-Hamid, and A. Váchalková, "Kojic acid-a new leading molecule for a preparation of compounds with an anti-neoplastic potential," Neoplasma, vol. 46, pp. 89-92, 1999.

[9] S. Emami, S. J. Hossemimehr, S. M. Taghdisi, and S. Akhlaghpoor, "Kojic acid and its manganese and zinc complexes as potential radioprotective agents," Bioorganic \& Medicinal Chemistry Letters, vol. 17, pp. 45-48, 2007.

[10] R. L. Pecsok, R. L. Meeker, and L. D. Shields, "Chelates of cadmium with kojic acid," Journal of the American Chemical Society, vol. 83, no. 9, pp. 2081-2085, 1961.
[11] Y. Murakami, "Complexing behavior of Kojic acid with metal ions. I. Mg(II) and $\mathrm{Mn}(\mathrm{II})$ Chelates," Bulletin of the Chemical Society of Japan, vol. 35, pp. 52-56, 1962.

[12] Y. Murakami and K. Mera, "Complexing behavior of kojic acid with metal ions. III. Infrared studies of bivalent metal-kojate chelates," Bulletin of the Chemical Society of Japan, vol. 39, pp. 396-397, 1966.

[13] F. Cecconi, C. A. Ghilardi, A. Ienco et al., "Different complexation properties of some hydroxy keto heterocycles toward beryllium(II) in aqueous solutions: experimental and theoretical studies," Inorganic Chemistry, vol. 41, no. 15, pp. 4006-4017, 2002.

[14] A. Zangl, P. Klüfers, D. Schaniel, and T. Woike, "Photoinduced linkage isomerism of $\mathrm{RuNO}^{6}$ complexes with bioligands and related chelators," Dalton Transactions, no. 6, pp. 1034-1045, 2009.

[15] M. Orio, C. Bochot, C. Dubois et al., "The versatile binding mode of transition-state analogue inhibitors of tyrosinase towards dicopper(II) model complexes: experimental and theoretical investigations," Chemistry, vol. 17, no. 48, pp. 1348213494, 2011.

[16] G. Crisponi, A. Dean, V. D. Marco et al., "Different approaches to the study of chelating agents for iron and aluminium overload pathologies," Analytical and Bioanalytical Chemistry, vol. 405, pp. 585-601, 2013.

[17] V. M. Nurchi, J. I. Lachowicz, G. Crisponi et al., "Kojic acid derivatives as powerful chelators for iron(III) and aluminium(III)," Dalton Transactions, vol. 40, no. 22, pp. 5984-5998, 2011.

[18] V. M. Nurchi, G. Crisponi, J. I. Lachowicz et al., "Iron(III) and aluminum(III) complexes with hydroxypyrone ligands aimed to design kojic acid derivatives with new perspectives," Journal of Inorganic Biochemistry, vol. 104, pp. 560-569, 2010.

[19] P. R. Sudhir, H. F. Wu, and Z. C. Zhou, "Probing the interaction of kojic acid antibiotics with iron(III) chloride by using electrospray tandem mass spectrometry," Rapid Communications in Mass Spectrometry, vol. 19, pp. 209-212, 2005.

[20] D. Sanna, L. Bíró, P. Buglyó, G. Micerac, and E. Garribba, "Transport of the anti-diabetic $\mathrm{VO}^{2+}$ complexes formed by pyrone derivatives in the blood serum," Journal of Inorganic Biochemistry, vol. 115, pp. 87-99, 2012.

[21] D. Sanna, P. Buglyó, L. Bíró, G. Micera, and E. Garribba, "Coordinating properties of pyrone and pyridinone derivatives, tropolone and catechol toward the $\mathrm{VO}^{2+}$ ion: an experimental and computational approach," European Journal of Inorganic Chemistry, vol. 2012, no. 7, pp. 1079-1092, 2012.

[22] R. Kakkar, R. Grover, and P. Gahlot, "Metal ion selectivity of hydroxamates: a density functional study," Journal of Molecular Structure: THEOCHEM, vol. 767, no. 1-3, pp. 175-184, 2006.

[23] J. P. Perdew, K. Burke, and M. Ernzerhof, "Generalized gradient approximation made simple," Physical Review Letters, vol. 77, no. 18, pp. 3865-3868, 1996.

[24] B. Delley, "An all-electron numerical method for solving the local density functional for polyatomic molecules," The Journal of Chemical Physics, vol. 92, no. 1, pp. 508-517, 1990.

[25] B. Delley, "Analytic energy derivatives in the numerical localdensity-functional approach," The Journal of Chemical Physics, vol. 94, no. 11, pp. 7245-7250, 1991.

[26] B. Delley, "Fast calculation of electrostatics in crystals and large molecules," Journal of Physical Chemistry, vol. 100, no. 15, pp. 6107-6110, 1996. 
[27] B. Delley, "From molecules to solids with the DMol3 approach," Journal of Chemical Physics, vol. 113, no. 18, pp. 7756-7764, 2000.

[28] N. Matsuzawa, J. Seto, and D. A. Dixon, "Density functional theory predictions of second-order hyperpolarizabilities of metallocenes," Journal of Physical Chemistry A, vol. 101, no. 49, pp. 9391-9398, 1997.

[29] R. Kakkar, P. N. Kapoor, and K. J. Klabunde, "First principles density functional study of the adsorption and dissociation of carbonyl compounds on magnesium oxide nanosurfaces," Journal of Physical Chemistry B, vol. 110, no. 51, pp. 25941-25949, 2006.

[30] N. A. Benedek, I. K. Snook, K. Latham, and I. Yarovsky, "Application of numerical basis sets to hydrogen bonded systems: a density functional theory study," Journal of Chemical Physics, vol. 122, no. 14, Article ID 144102, 2005.

[31] B. Delley, "Hardness conserving semilocal pseudopotentials," Physical Review B, vol. 66, Article ID 155125, 2002.

[32] C. U. Singh and P. A. Kollman, "An approach to computing electrostatic charges for molecules," Journal of Computational Chemistry, vol. 5, pp. 129-145, 1984.

[33] I. Mayer, "Bond orders and valences from ab initio wave functions," International Journal of Quantum Chemistry, vol. 29, pp. 477-483, 1986.

[34] K. B. Wiberg and P. R. Rablen, "Comparison of atomic charges derived via different procedures," Journal of Computational Chemistry, vol. 14, pp. 1504-1518, 1993.

[35] R. Kakkar, R. Grover, and P. Gahlot, "Density functional study of the properties of isomeric aminophenylhydroxamic acids and their copper (II) complexes," Polyhedron, vol. 25, no. 3, pp. 759766, 2006.

[36] R. Kakkar and C. Singh, "Theoretical study of the kojic acid structure in gas phase and aqueous solution," International Journal of Quantum Chemistry, vol. 111, no. 15, pp. 4318-4329, 2011.

[37] D. T. Richens, The Chemistry of Aqua Ions, John Wiley \& Sons, New York, NY, USA, 1997.

[38] R. G. Parr and R. G. Pearson, "Absolute hardness: companion parameter to absolute electronegativity," Journal of the American Chemical Society, vol. 105, no. 26, pp. 7512-7516, 1983.

[39] R. G. Pearson, "Hard and soft acids and bases," Journal of the American Chemical Society, vol. 85, no. 22, pp. 3533-3539, 1963.

[40] R. B. Martin, "A stability ruler for metal ion complexes," Journal of Chemical Education, vol. 64, p. 402, 1987.

[41] H. Sigel and D. B. McCormick, "Discriminating behavior of metal ions and ligands with regard to their biological significance," Accounts of Chemical Research, vol. 3, pp. 201-208, 1970.

[42] J. P. Glusker, "Structural aspects of metal liganding to functional groups in proteins," Advances in Protein Chemistry, vol. 42, pp. 1-76, 1991.

[43] L. Rulíśek and J. Vondrášek, "Coordination geometries of selected transition metal ions $\left(\mathrm{Co}^{2+}, \mathrm{Ni}^{2+}, \mathrm{Cu}^{2+}, \mathrm{Zn}^{2+}, \mathrm{Cd}^{2+}\right.$, and $\mathrm{Hg}^{2+}$ ) in metalloproteins," Journal of Inorganic Biochemistry, vol. 71, pp. 115-127, 1998.

[44] J. Bjerrum and C. K. Jorgenssen, "Crystal field stabilization and tendency towards complex formation of first transition group elements," Recueil des Travaux Chimiques des Pays-Bas, vol. 75, pp. 658-664, 1956.

[45] L. E. Orgel, An Introduction to Transition Metal Chemistry, Ligand Field Theory, Methuen, London, UK, 1966. 

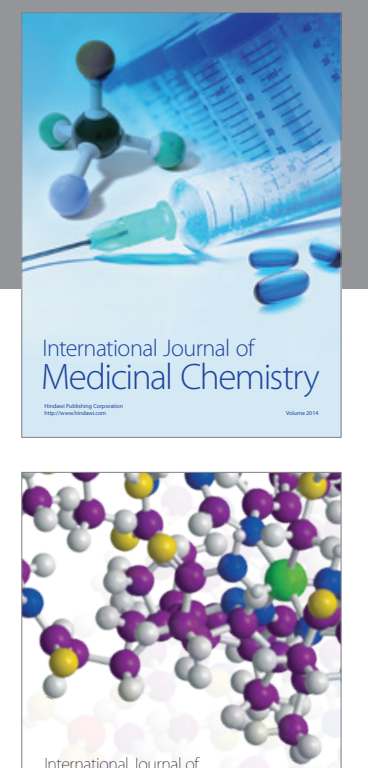

\section{Carbohydrate} Chemistry

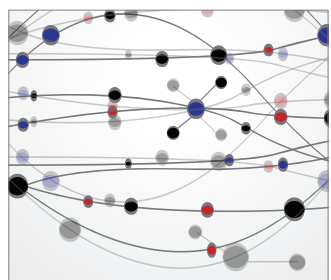

The Scientific World Journal
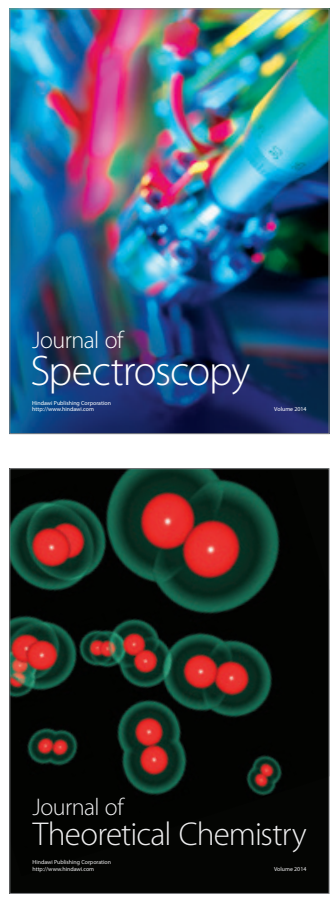
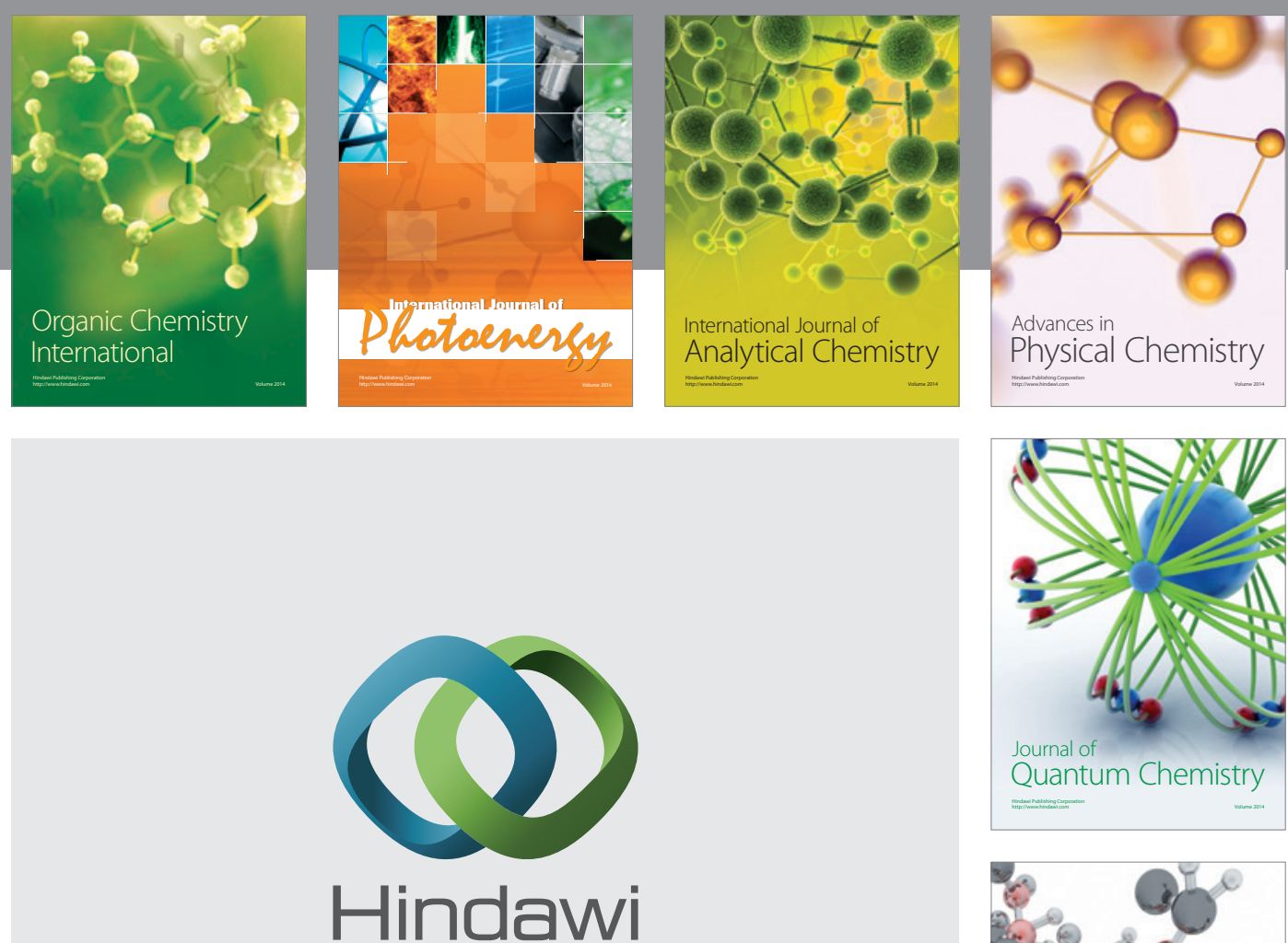

Submit your manuscripts at

http://www.hindawi.com

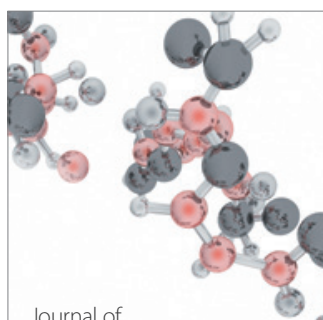

Analytical Methods

in Chemistry

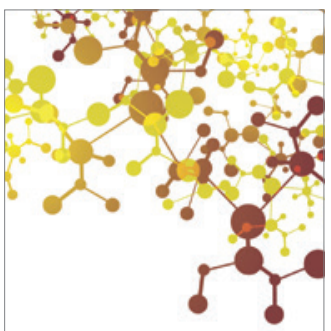

Journal of

Applied Chemistry

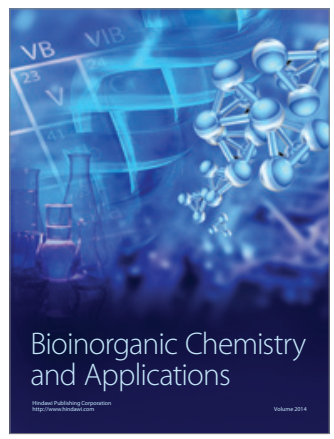

Inorganic Chemistry
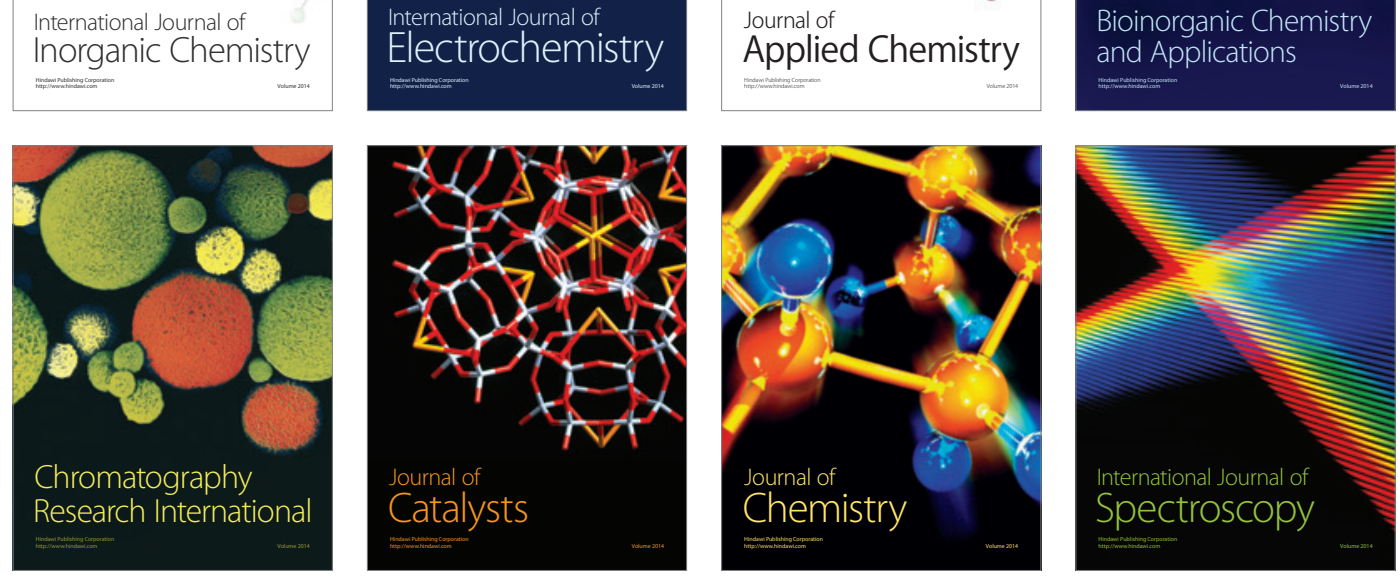